\title{
Leis deuteronômicas favoráveis à preservação de fauna e flora
}

\author{
Deuteronomic laws favourable to the
}

preservation of fauna and flora

MATTHIAS GRENZER ${ }^{\mathrm{a}}$

FERNANDO GROSS

\section{Resumo}

Embora o interesse pela natureza tenha existido nas mais diversas épocas, observa-se, a partir dos anos 1970, um ambientalismo que origina organizações não governamentais, movimentos ecológicos e partidos verdes, insistentes numa consciência favorável à proteção do planeta Terra. Em oposição a crescimentos econômicos que resultam na devastação da natureza, favorece-se um uso sustentável dos recursos naturais, incluindose a exigência de preservação da fauna e da flora. No estudo aqui apresentado, procurase pela temática da ecologia na literatura bíblica. Exemplarmente, são relidas as formulações jurídicas no Decálogo (Dt 5,6-21) e no Código Deuteronômico (Dt 12-26), a fim de descrever, por meio de um estudo exegético, o conteúdo das leis deuteronômicas que, a partir do fim do século VII a.C., insistem na preservação da fauna e da flora.

Palavras-chave: Deuteronômio. Preservação. Fauna. Flora.

\section{Abstract}

Although the interest in nature existed in the most diverse periods, from the seventies of the twentieth century, it is observed environmentalism that originates from nongovernmental organizations, ecological movements and green parties, insistent on a

\footnotetext{
a Pontifícia Universidade Católica de São Paulo (PUC-SP), São Paulo, SP, Brasil. Doutor em Teologia, e-mail: mgrenzer@pucsp.br

b Pontifícia Universidade Católica de São Paulo (PUC-SP), São Paulo, SP, Brasil. Mestre em Teologia, e-mail: grossfernando@gmail.com
} 
conscience favorable to the protection of planet earth. In opposition to economic growth that results in the devastation of nature, sustainable use of natural resources is favored, including the requirement of the preservation of fauna and flora. In the study presented here, we search for ecology in biblical literature. The juridical formulations of the Decalogue (Deut. 5:6-21) and the Deuteronomic Code (Deut. 12-26) are read in detail to describe, through an exegetical study, the content of those Deuteronomic laws which, from the end of the seventh century $B C$, already insist on the preservation of fauna and flora.

Keywords: Deuteronomy. Preservation. Fauna. Flora.

\section{Introdução}

A literatura bíblica contempla o mundo e tudo o que pertence a ele como criação divina. Nesse sentido, afirma que a origem, a permanência e o destino de todos os seres se encontra no Senhor, Deus de Israel, ao considerálo como criador (cf. JANOWSKI; SCHOLTISSEK, 2016, p. 385-387). Em contrapartida, como criação, o cosmo, a natureza e o próprio ser humano remetem, de acordo com a reflexão teológica promovida pelos textos bíblicos, ao reconhecimento da existência e da atuação continuada do criador, sendo que o olhar para a criação se transforma, continuamente, em louvor ao Deus criador.

Consequentemente, a literatura bíblica propõe que, do reconhecimento do criador, nasça um profundo respeito à criação, o qual deve resultar em uma consciência renovada, capaz de favorecer comportamentos que visem ao “cuidado da casa comum" (FRANCISCO, 2015). Em outras palavras, embora os textos bíblicos convidem o homem a descobrir-se como quem "subjuga" a criação e a “domina” (Gn 1,28), participando, dessa forma, do domínio absoluto do criador, o homem deve entender seu domínio como quem "se coloca a serviço" e "cuida" da terra, experimentando-a como um imenso “jardim de delícias” e/ou "prazeres" (Gn 2,15). É dessa forma que a Bíblia desenvolve uma verdadeira ecoteologia (cf. ESPÍNDOLA GARCÍA; LODOÑO, 2016, p. 137-166).

Diante disso, o estudo aqui apresentado se propõe a investigar algumas formulações jurídicas pertencentes ao livro bíblico do Deuteronômio. Nelas, o legislador israelita, aparentemente, prescreve, de forma direta, a preservação da natureza. Nem sempre tais textos do livro do Deuteronômio são 
mencionados e estudados de forma pormenorizada, quando se procura pela eventual contribuição da Bíblia à temática da ecologia (cf. HAREUVENI, 1974), ou apenas alguns deles entram no foco (cf. REIMER, 2010, p. 80-86). No entanto, caso se confirme a impressão de que existem leis no Decálogo (Dt 5,621) e no Código Deuteronômico (Dt 12-26) que diretamente insistem na preservação da natureza, será possível afirmar que a Bíblia, em seu conjunto, de forma alguma favorece um domínio violento do homem sobre a terra, no sentido de tolerar-se um tipo de exploração da natureza que incorra no risco de, definitivamente, causar o esgotamento e/ou desaparecimento de determinado recurso natural.

Em 2019, o assunto aqui tratado ganha ainda maior relevância em vista do Sínodo da Amazônia, encontro planejado para o mês de outubro na cidade de Roma. Bispos e outros peritos dos nove países nos quais se estende tal região irão debater o tema: "Amazônia: novos caminhos para a Igreja e para uma ecologia integral" (HUMMES, 2019, p. 15). Entre outras questões, será visado justamente como, a partir de um diálogo verdadeiro, os povos existentes nessa região podem evitar a devastação da sociobiodiversidade da Amazônia (cf. OLIVEIRA, 2019, p. 3-14).

Todavia, a literatura bíblica é um dos patrimônios culturais a serviço da humanidade, uma vez que busca a sobrevivência digna de todas as etnias e da natureza. Nesse sentido, o estudo exegético aqui favorecido, focando algumas formulações jurídicas no livro do Deuteronômio, se propõe a contribuir com a tarefa de disponibilizar, da forma mais exata possível, a sabedoria ímpar contida na literatura bíblica.

\section{Preservação da fauna}

Diversas leis no livro do Deuteronômio versam sobre a proteção de animais que, em determinado momento, se encontram numa situação exigente e/ou delicada, seja por causa dos trabalhos por eles realizados, seja por um acidente que lhes coloca a sobrevivência em risco. Para esses momentos, o legislador israelita parece prescrever uma postura que leva o homem a reconhecer determinados limites no que se refere à exploração da natureza. Embora as leis deuteronômicas não possam ser comparadas a um 
código moderno de proteção aos animais, aparentemente já existe nelas uma ética de proteção aos animais capaz de regularizar, numa direção protecionista, as relações entre o ser humano e os animais.

\section{Descanso sabático para jumento, gado bovino e gado qualquer (Dt 5,14)}

Surpreendentemente, o Decálogo (Ex 20,2-17; Dt 5,6-21) inclui os animais quando prescreve o descanso sabático. Eis a formulação em Dt 5,12-15:

(12) Cuidarás do dia do sábado para santificá-lo, assim como o SENHOR, teu Deus, te ordenou. (13) Seis dias servirás e realizarás todo o teu trabalho. (14) O sétimo dia, porém, é sábado para o SENHOR, teu Deus. Não realizarás nenhum trabalho, nem tu, nem teu filho, nem tua filha, nem teu servo, nem tua serva, nem teu gado bovino, nem teu jumento, nem gado qualquer teu, nem teu imigrante que está entre teus portões, a fim de que, igual a ti, teu servo e tua serva repousem. (15) Lembrar-te-ás de que foste servo na terra do Egito e de que, com mão forte e braço estendido, o SENHOR, teu Deus, te fez sair de lá. Por isso, o SENHOR, teu Deus, te ordenou a pôr em prática o dia do sábado.

De maior interesse aqui é o que o legislador israelita diz sobre "gado bovino", "jumento" e "gado qualquer" no v. 14. Numa lista formada por nove elementos, ao citar, de forma exemplar, quem "não deve realizar trabalho nenhum" em dia de sábado (v. 12), animais são mencionados três vezes. A versão do decálogo no livro do Êxodo menciona apenas o "gado" (Ex 20,10), sendo que, em sua lista formada por apenas sete elementos, não há referência expressa a "gado bovino" nem a “jumento" (Dt 5,14). Percebe-se com isso que a versão deuteronômica do decálogo visa ao descanso sabático dos animais de modo mais insistente e, retoricamente, reforçado.

Em todo caso, o terceiro mandamento do decálogo favorece "o aspecto social do sétimo dia como dia de repouso", ao propor, "eficazmente", "beneficiar pessoas ameaçadas pela miséria e animais de carga", reconhecendo, assim, "o senhorio do Senhor sobre os recursos" disponibilizados pela natureza e/ou pela criação (OTTO, 2012, p. 739). Eis a "santificação do sábado" (v. 12) religiosamente prevista. Ela deve culminar, pois, em relações renovadas com as pessoas socialmente mais dependentes e 
no respeito aos animais, em especial aos domésticos que diretamente convivem com o homem.

No decálogo deuteronômico, a cláusula final, com seu verbo aqui traduzido como "a fim de que... repousem", visa, de forma direta, ao "servo" e à "serva" (v. 14c). No entanto, pelo contexto dessa mesma frase se percebe que "jumento", "gado bovino" e "qualquer gado" também têm direito a repouso, uma vez que a formulação jurídica, expressamente, diz que eles "não irão realizar nenhum trabalho" (v. 14b). Essa percepção, por sua vez, se encontra ainda mais garantida quando se reconhece que o decálogo deuteronômico "acolhe a determinação final de uma formulação a respeito do sábado presente no Código da Aliança (Ex 20,22-23,33)" (MARKL, 2007, p. 215). Ali, pois, se prescreve, de forma expressa, também o repouso dos animais: “Durante seis dias farás teus trabalhos e, no sétimo dia, descansarás, a fim de que teu gado bovino e teu jumento repousem, e o filho de tua serva e o imigrante tomem fôlego" (Ex 23,12).

\section{Ajuda a gado bovino, gado miúdo e jumento desgarrados ou caídos (Dt 22,1-4)}

Um conjunto de formulações jurídicas no Código Deuteronômico (Dt 1226) insiste na preservação de animais domésticos desgarrados e/ou acidentados. Eis a tradução das leis em Dt 22,1-4:

(1) Não verás o gado bovino de teu irmão ou o gado miúdo dele desgarrados. Não te ocultarás deles. Sem falta os levarás de volta a teu irmão. (2) Caso teu irmão não estiver perto de ti ou não o conheceres, o acolherás no interior de tua casa. Estará contigo até teu irmão o procurar; então lho devolverás. (3) Assim farás com o jumento dele e assim farás com a vestimenta dele. Assim farás com qualquer coisa perdida de teu irmão, sendo que se perde o que é dele, mas o encontras. Não poderás ocultar-te. (4) Não verás o jumento de teu irmão ou o gado bovino dele caídos no caminho! Não te ocultarás deles! Com ele, sem falta o farás erguer-se!

As leis no Código Deuteronômico acolhem formulações jurídicas mais antigas do Código da Aliança (Ex 20,22-23,33): "Se deparares o gado bovino de teu inimigo ou o jumento vagueador dele, sem falta lho levarás de volta. Se assistires ao jumento de quem te odeia agachando-se debaixo de sua carga, 
desistirás de abandoná-lo. Sem falta, o deixarás com ele” (Ex 23,4-5). Nesse caso se trata, expressamente, de "gado bovino" e/ou "jumento" do "inimigo" ou de quem "cultiva ódio" para com aquele que encontra o animal sofrendo. Não obstante, "a ajuda necessária é imposta de forma rígida” pelo legislador israelita, sendo que tal solidariedade "deve prevalecer até sobre as inimizades e ódios existentes" (GRENZER, 2007, p. 161).

O legislador deuteronômico, no entanto, ao prescrever o socorro ao animal que sofre, formula seu éthos de fraternidade dirigindo-se a todos os membros da comunidade religiosa. Por cinco vezes, as leis em Dt 22,1-4 mencionam expressamente o "irmão" ( $\left.v \cdot 1^{2 x} \cdot 2^{2 x} \cdot 4\right)$. Além disso, oito sufixos pronominais - aqui traduzidos como "dele" (v. 1a.3a.3b.d.4a), “o” (v. 2b), "Iho" (v. 2e) e "com ele" (v. 4c) — se referem ao "irmão". Enfim, não importa se esse “irmão” é ou não de “perto" (v. 2a), nem se ele “é conhecido” (v. 2b) — algo, aparentemente, pressuposto em Ex 23,4-5 (cf. OTTO, 2016, p. 1694) mas é preciso garantir que nenhum irmão "se oculte" ou "desapareça da presença de" (v. 1b.3f.4b) um animal que precisa ser ajudado.

De modo específico, as primeiras leis em Dt 22,1-3 visam a um "gado bovino" - touro, boi, vaca, novilho, bezerro — ou a um "gado miúdo" — ovelha, cabra, carneiro, bode, cordeiro, cabrito - que "se desgarrou" ou “dispersou” (v.1). As últimas leis em Dt 22,4, por sua vez, olham para o jumento ou gado bovino (v. 4a) enquanto animais que, na sociedade predominantemente agrícola do antigo Israel, se destacam por sua força. "Até em terreno difícil", jumento e jumenta transportam pessoas (Ex 4,20; Nm 22,22; Jz 12,14; $1 \mathrm{Sm}$ 25,20; 2Sm 16,2) e as mais diversas cargas (Gn 42,26; Ex 23,5; 1Sm 25,18) (RIEDE, 2010, p. 1). Existe, nos textos da Bíblia Hebraica, até a

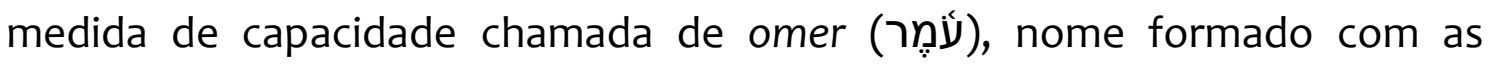
mesmas consoantes do substantivo jumento (חמור), mudando apenas a vocalização. Trata-se da "carga que um jumento consegue carregar”, ou seja, de aproximadamente duzentos litros (WINKLER, 2016, 1.3.1.1). Além disso, lavrando a terra, jumento e gado bovino puxam o arado (Dt 22,10; Is 30,24), realizando um trabalho que exige força bem superior à de um homem.

Não obstante, como animais fortes e/ou extremamente úteis ao homem, "gado bovino" (v. 1a.4a), "gado miúdo" (v. 1a) e "jumento" (v. 3a.4a) podem sofrer diversos perigos. Ora "se desgarram" (v. 1a), no sentido de seu 
dono os "perder" (v. 3c-d), ora "caem no caminho" (v. 4a), provavelmente debaixo de sua (sobre)carga. Para o legislador deuteronômico, nesse momento "não prevalece o aspecto da propriedade, mas que os animais continuem vivos e que, assim, possam continuar a ser úteis", pois "não querer ver o dano potencial" para o irmão não corresponderia ao "espírito fraterno" numa sociedade solidária (BRAULIK, 1992, p. 160). Ao contrário, a preocupação com os animais que sofrem quer unir as pessoas. Nesse sentido, em vez de "se ocultar" (v. 4b), a pessoa deve "erguer" um animal caído "com ele" (v. 4c), ou seja, junto a seu “irmão" (v. 4a).

\section{Preservação do pássaro-mãe (Dt 22,6-7)}

Pássaros sempre fascinaram o homem. Assim, tais animais também ganharam presença no imaginário religioso do antigo Israel (cf. SI 84,4) (cf. GRENZER; BREY, 2017). A Bíblia Hebraica menciona quarenta e sete vezes o termo comumente traduzido como pássaro (ציפור), além de lembrar diversas espécies desse animal. Seja visto aqui o que a lei em Dt 22,6-7 formula a respeito dos pássaros:

(6) Se, no caminho, se encontrar um ninho de pássaros diante de ti, em qualquer árvore ou sobre o chão, com passarinhos ou ovos, e a mãe estiver agachada sobre os passarinhos ou sobre os ovos, não pegarás a mãe junto com os filhotes! (7) Sem falta, soltarás a mãe! Poderás pegar para ti os filhotes, a fim de que ocorra o bem a ti e te demores em dias!

Na linha do raciocínio das leis em Dt 22,1-4, também essa formulação jurídica visa a um comportamento ante os animais que se interessa pela continuidade da existência deles. Nesse sentido, o legislador deuteronômico, novamente, "impõe limites" a seu ouvinte-leitor ao insistir em determinada "restrição ao modo de o homem lidar com a natureza", prescrevendo, "no interesse dos próprios endereçados, que se proteja o patrimônio da avifauna da exterminação dela" (OTTO, 2016, p. 1699).

Prevê-se, pois, que diversos interesses possam ser reconciliados. Por um lado, pois, o homem precisa alimentar-se. Em vista disso, "poderás pegar para ti os filhotes" (v. 7b). Por outro lado, porém, o homem deve ter "respeito aos 
portadores da vida", de modo que "conserve o pássaro-mãe, a fim de, através dela, garantir a transmissão da vida e o alimento futuro" (BRAULIK, 1992, p. 162). Quer dizer, de forma alguma deve ocorrer a extinção de uma espécie animal. Por isso a ordem "Sem falta, soltarás a mãe!” (v. 7a), a fim de que ela, futuramente, ponha e choque outros ovos.

\section{Gado bovino debulhador não amordaçado (Dt 25,4)}

Outra lei deuteronômica chama a atenção do ouvinte-leitor quanto à preservação da fauna. Eis a formulação jurídica em Dt 25,4:

(4) Não amordaçarás o gado bovino quando ele debulhar.

Para tirar os grãos das espigas, os feixes amarrados de cereais eram levados à eira, lugar rochoso ou com chão firmemente batido, onde, caso houvesse um volume grande, um boi ou um jumento, com seus cascos duros ou, eventualmente, puxando um trenó com ferros afiados embaixo dele, passava por cima dos cereais estendidos, a fim de extrair os grãos e cortar as outras partes da planta, como o caule e a espiga. Em seguida, removendo ou padejando o material diversas vezes com uma forquilha e uma pá, o agricultor separava os grãos mais pesados das partes mais leves, ou seja, do restolho mais grosso e da palha mais fina (cf. KOENEN, 2007).

Contudo, aparentemente, "se amordaçava o focinho dos animais usados para a debulha, a fim de que, ao debulharem, não comessem os cereais, o que era duplamente prejudicial: ora por reduzir o rendimento do trabalho animal, ora por reduzir a quantia de cereais" (OTTO, 2017, p. 1849). O legislador deuteronômico, no entanto, proíbe tal prática, pois vê nisso "uma dureza inadmissível em relação aos animais", uma vez que "se impossibilita que eles comam, embora, constantemente, a ração esteja diante dos olhos deles" (OTTO, 2017, p. 1849). Afinal, “o justo deve conhecer o fôlego de seu gado” (Pr $12,10)$. 
Respeito à desproporção entre gado bovino e jumento (Dt 22,10)

Outra lei deuteronômica que, eventualmente, vise à proteção da fauna se ouve ou lê em Dt 22,10:

(10) Não ararás juntamente com um gado bovino e com um jumento!

Ao imaginar, pois, um gado bovino e um jumento debaixo da mesma canga, percebe-se que cansaços e desconfortos desproporcionais são provocados pelo emprego de animais de tamanhos diferentes em um trabalho fisicamente exigente. Ambos os animais chegariam a sofrer desnecessariamente, uma vez que o esforço de puxar o arado não se encontraria dividido de forma proporcional.

\section{Preservação da flora}

Semelhantemente às leis deuteronômicas que, de forma paradigmática, se preocupam com a preservação da fauna, também se encontram algumas formulações jurídicas no quinto livro do Pentateuco que visam à preservação da flora. No caso, o legislador deuteronômico olha para as plantas que o homem cultiva a fim de alimentar-se dos frutos produzidos por elas.

Proteção às árvores frutíferas na guerra (Dt 20,19-20)

Em determinados momentos históricos, fauna e flora encontram-se mais ameaçadas em sua sobrevivência do que comumente. Na antiguidade, sobretudo secas prolongadas e guerras podiam provocar consequências graves à natureza. Nesse sentido, a formulação em Dt 20,19-20 merece atenção:

(19) Se cercares uma cidade por muitos dias, para combater contra ela e capturá-la, não danificarás as árvores dela ao brandir contra elas o machado, porque delas te alimentarás. Não as cortarás. Por acaso, a árvore do campo é, de fato, um ser humano para vir diante de ti em meio ao cerco? (20) Somente poderás danificar uma árvore da qual sabes que ela não é uma árvore frutífera. Poderás cortá-la e construir um cerco contra a cidade, sendo que esta promove um combate contigo até ela vir abaixo. 
A formulação jurídica visa à fase prolongada de guerra em que uma cidade inimiga é cercada. Ora para avisar os cercados sobre a seriedade do ataque e/ou a urgência de se entregarem, ora para demonstrar que nenhum futuro lhes seria possível em razão da destruição de um dos recursos mais importantes para a alimentação dos sobreviventes, os atacantes chegavam a destruir as árvores frutíferas ao redor do lugar sitiado. Nesse sentido, "a aniquilação da população de árvores se encontra comprovada, por palavras e imagens, para a técnica egípcia e assíria do cerco", sendo que tal "vandalismo militar também existia por parte de Israel (cf. 2Rs 3,19.25)" (BRAULIK, 1992, p. 151).

O legislador deuteronômico, porém, investe no princípio ético da "restrição do acesso" aos recursos naturais, "em favor da proteção da vida do ser humano e do ambiente natural dele", e isso justamente ao "declarar tabus as árvores frutíferas como merecedoras de proteção numa difícil situação militar”, sendo que “a superação de si mesmo e a autolimitação são ao sábio algo superior à conquista de uma cidade", e que "a imposição triunfal do poder militar se concretiza justamente na desistência da vingança e na promoção da solidariedade com o inimigo (cf. Pr 25,21-22)" (OTTO, 2016, p. 1593.1595).

Aliás, no que se refere às árvores, é preciso pensar em longos prazos. Imaginando, pois, que uma oliveira plantada dá seu fruto apenas após sete anos, e uma tamareira, após vinte anos, a danificação de árvores frutíferas é algo extremamente prejudicial à população1. Além disso, as árvores frutíferas jamais poderão ser contempladas como inimigas do ser humano, pois elas não são capazes de atacá-lo (v. 19e). Nesse sentido, "uma árvore não é um ser humano" (v. 19e). Ao contrário, em vez de serem hostis ao ser humano, as “árvores frutíferas" apenas o "alimentam" (v. 19c.20c; cf. Gn 2,9.16).

\footnotetext{
${ }^{1}$ Ver também a seguinte história no Talmude a respeito do estudioso judeu Choni ha-M'agel, do século I d.C.: "Caminhando um dia no campo, ele viu um homem plantando uma alfarrobeira e Ihe pergunta: 'Quanto tempo será preciso para que uma alfarrobeira produza seus frutos?' O velho homem Ihe responde: 'Setenta anos'. Surpreso, Choni pergunta: 'Velho homem, tu pensas viver ainda setenta anos para comer desses frutos da árvore que tu estás plantando agora?' O velho homem, rindo, Ihe respondeu: 'Quando vim a este mundo, eu já encontrei alfarrobeiras plantadas por outros. Agora, eu planto novas árvores para meus filhos e para os filhos dos meus filhos'" (Talmude da Babilônia, Tratado Taanit, 23a. In: FIELDS, 2017, p. 200).
} 
Enfim, com certa ironia, as árvores frutíferas dão ao homem uma lição de vida, a qual sempre será acompanhada de conotações religiosas². Por mais que o ser humano, pois, "branda seu machado contra a árvore" e a "danifique" (v. 19d), ainda existe "esperança para a árvore", porque, ao contrário do homem, "mesmo cortada, a árvore ainda fará brotar", sendo que "seu rebento não cessa" (Jó 14,7). Quer dizer, ainda que o ser humano possa "danificar" amplamente "as árvores" (v. 19b.20a), destruí-las de forma definitiva, aparentemente, não está ao seu alcance.

\section{Respeito às plantações (Dt 20,6; 23,25-26; 24,19-21)}

Embora as leis estudadas a seguir não insistam, diretamente, na preservação da flora, sejam elas mencionadas aqui para perceber-se como o legislador deuteronômico, por motivos religiosos, favorece determinado respeito às plantas cultivadas pelo homem. Eis a formulação jurídica em Dt 20,6:

(6) Quem é o homem que plantou uma vinha e não a vindimou? Que vá e volte à sua casa, a fim de que não morra no combate e de que outro homem a vindime!

A lei libera do serviço militar o homem que ainda não realizou a primeira colheita numa vinha nova plantada por ele. De acordo com Dt 28,30, pois, seria uma maldição se isso acontecesse. Aliás, segundo Lv 19,23-24, a primeira vindima somente ocorre quando as videiras produzem frutos pela quinta vez. Todavia, as leis deuteronômicas preveem, no momento do recrutamento de soldados para uma guerra, que "se dê o espaço necessário à humanização", visando-se à "felicidade privada do soldado" ao garantir-lhe "o rendimento de seu trabalho" (BRAULIK, 1992, p. 147). Quer dizer, assim como ele teria direito de desfrutar de uma "casa nova" (Dt 20,5) ou de ficar em casa por ter

\footnotetext{
${ }^{2}$ Cabe lembrar aqui a tomada de posição do rabi Yohanan ben Zakai, aluno de Hillel, que dirigiu o sinédrio durante a tomada de Jerusalém pelos romanos no ano 70 d.C.: "Se estivermos plantando uma árvore e chegar alguém anunciando a chegada do Messias, aquele que devia trazer a paz para a humanidade, não deveremos parar de plantar a árvore. Antes termine de plantar a árvore, depois você poderá ir acolher o Messias" (Talmude da Babilônia, Tratado Pirkei Avot, 31. In: FIELDS, 2017, p. 200).
} 
recentemente desposado uma mulher (Dt 20,7), também não deve ser chamado ao combate em respeito à vinha nova plantada por ele (Dt 20,6).

Percebe-se, assim, que o legislador deuteronômico reconhece as plantações com suas plantas como expressão da bênção divina. Com isso, também reconhece o direito de todos se alimentarem delas. Nesse sentido, qualquer pessoa tem licença de "entrar na vinha de seu próximo e comer uvas até sua alma ficar saciada, mas sem colocar algo no cesto dele" (Dt 23,25), ou de "entrar na seara de seu próximo e arrancar espigas com sua mão, porém, sem meter a foice na seara de seu próximo" (Dt 23,26).

Aqui também cabe menção às leis referentes ao direito de rebusca por parte do "imigrante", do “órfão" e da "viúva”, aos quais pertencem o "feixe esquecido no campo", o que ficou após a primeira "sacudida" dos ramos "da oliveira" e o que restou após a "vindima na vinha" (Dt 24,19-21). Afinal, o legislador deuteronômico imagina que os donos de campos, vinhas e olivais e, consequentemente, da produção de cereais, uvas e azeitonas - somente serão "abençoados pelo Senhor", Deus de Israel, caso garantam que suas plantações alimentem a todos (Dt 24,19e).

\section{Considerações finais}

Algumas leis deuteronômicas, surpreendentemente, insistem na preservação de fauna e flora ao visarem, de forma paradigmática, à proteção de animais domésticos e de plantas cultivadas pelo homem. Toda a natureza não entra nesse horizonte, uma vez que, na antiguidade, o homem ainda se sentia ameaçado pelo mundo selvagem, disputando com este os diversos espaços, sem que pudesse exercer um domínio total sobre a natureza. Onde, porém, o homem conseguia instalar-se em busca de sua sobrevivência, o legislador deuteronômico favorece o respeito à fauna e à flora.

Nesse sentido, algumas leis deuteronômicas favorecem uma ética de proteção aos animais, impondo limites no que se refere à exploração ilimitada da natureza. Prescreve-se, assim, o descanso sabático para jumento, gado bovino e gado qualquer ( $\mathrm{Dt} 5,14$ ). Não se deve explorar, de forma ininterrupta, a força dos animais, especialmente dos animais de carga. Assim como o homem, também o animal deve descansar, a fim de recuperar seu alento. 
Semelhantemente, o legislador deuteronômico prescreve a ajuda a gado bovino, gado miúdo e jumento desgarrados ou caídos (Dt 22,1-4). Prevalece o imperativo de não assistir ao animal acidentado sem ajudá-lo. Além disso, o legislador deuteronômico se propõe a proteger a existência das espécies, quando insiste, de forma exemplar, na preservação da vida do pássaro-mãe ao se encontrar um ninho com ela sentada sobre seus ovos ou filhotes (Dt 22,67). Outras duas leis deuteronômicas parecem visar ao bom trato dos animais, quando é definido que o gado bovino debulhador não pode ser amordaçado (Dt 25,4) e que o gado bovino e o jumento, por serem de tamanho diferentes, não devem ser juntados debaixo da mesma canga para, conjuntamente, puxarem o arado (Dt 22,10).

A intenção de preservar a flora vem à tona quando o legislador deuteronômico, diretamente, prescreve a proteção das árvores frutíferas na guerra (Dt 20,19-20) e, indiretamente, prevê o respeito às plantações (Dt 20,6; 23,25-26; 24,19-21), a fim de que estas alimentem a todos. Sabe-se, pois, dos danos causados por destruições desnecessárias, uma vez que o ser humano, também, em vista das futuras gerações, depende das plantas.

Enfim, o livro do Deuteronômio não insiste apenas indiretamente na proteção de animais e plantas, por compreender a natureza como criação divina (cf. Dt 10,14; 33,13-16), mas diretamente, quando, por meio de determinadas leis exemplares, se mostra favorável à preservação de fauna e flora. A todo tipo de vandalismo, destruição inútil, maus-tratos e exploração ilimitada da natureza, pois, o legislador deuteronômico opõe o mandamento: "Não danificarás!" (Dt 20,19b).

\section{Referências}

BRAULIK, G. Deuteronomium II. 16,18-34,12. Würzburg: Echter, 1992.

ESPÍNDOLA GARCÍA, L. G.; LODOÑO, A. Perspectiva a partir da Bíblia. In: MURAD, A. Ecoteologia. Um mosaico. São Paulo: Paulus, 2016.

FIELDS, H. J. La Torah commentée pour notre temps. Les Nombres et le Deutéronome. Paris: Le Passeur, 2017.

FRANCISCO. Carta Encíclica Laudato Si': sobre o cuidado da casa comum. São Paulo: Paulinas, 2015. 
GRENZER, M. Junto ao inimigo (Ex 23,1-8). In: GRENZER, M. O projeto do êxodo. 2. ed. São Paulo: Paulinas, 2007.

GRENZER, M.; BREY, P. Águia ou abutre? (Ex 19,4). Revista de Cultura Teológica, n. 90, p. 347-360, jul./dez. 2017.

HAREUVENI, N. Ecology in the Bible. Kiryat Ono, Israel: Neot Kedumim, 1974.

HUMMES, Cardeal Dom C. O Sínodo para a Amazônia. São Paulo: Paulus, 2019.

JANOWSKI, B.; SCHOLTISSEK, K. Schöpfung. In: BERLEJUNG, A.; FREVEL, C. (Orgs.). Handbuch theologischer Grundbegriffe zum Alten und Neuen Testament. 5. ed. Darmstadt: Wissenschaftliche Buchgesellschaft, 2016. p. 385-387.

KOENEN, K. Dreschen und worfeln. In: Das Wissenschaftliche Bibellexikon im Internet, 2007. Disponível em: <http://www.wibilex.de>. Acesso em: 19 abr. 2019.

MARKL, D. Der Dekalog als Verfassung des Gottesvolkes. Die Brennpunkte einer Rechtshermeneutik des Pentateuch in Ex 19-24 und Dtn 5. Freiburg: Herder, 2007.

OLIVEIRA, M. M. de. A Igreja na multiplicidade amazônica. Vida Pastoral, n. 327, p. 314, 2019.

OTTO, E. Deuteronomium 1-11. Zweiter Teilband: 4,44-11,32. Freiburg: Herder, 2012.

OTTO, E. Deuteronomium 12-34. Erster Teilband: 12,1-23,15. Freiburg: Herder, 2016.

OTTO, E. Deuteronomium 12-34. Zweiter Teilband: 23,16-34,12. Freiburg: Herder, 2017.

REIMER, H. Bíblia e Ecologia. São Paulo: Reflexão, 2010.

RIEDE, P. Esel. In: Das Wissenschaftliche Bibellexikon im Internet, 2010. Disponível em: <http://www.wibilex.de>. Acesso em: 06 abr. 2019.

WINKLER, M. Masse/Gewichte (AT). In: Das Wissenschaftliche Bibellexikon im Internet, 2016. Disponível em: <http://www.wibilex.de>. Acesso em: 06 abr. 2019. 